\title{
Withaninsams A and B: Phenylpropanoid Esters from the Roots of Indian Ginseng (Withania somnifera)
}

\author{
Su Cheol Baek ${ }^{1}$, Seoyoung Lee ${ }^{2}$, Sil Kim ${ }^{1}$, Mun Seok Jo ${ }^{1}$, Jae Sik Yu ${ }^{1}$, Yoon-Joo Ko ${ }^{3}$, \\ Young-Chang Cho ${ }^{2}$ and Ki Hyun Kim ${ }^{1, * \mathbb{D}}$ \\ 1 School of Pharmacy, Sungkyunkwan University, Suwon 16419, Korea; schii513@daum.net (S.C.B.); \\ malin_1272@naver.com (S.K.); anstjr920827@gmail.com (M.S.J.); jsyu@bu.edu (J.S.Y.) \\ 2 College of Pharmacy, Chonnam National University, Gwangju 61186, Korea; 96_29@naver.com (S.L.); \\ yccho@jnu.ac.kr (Y.-C.C.) \\ 3 Laboratory of Nuclear Magnetic Resonance, National Center for Inter-University Research \\ Facilities (NCIRF), Seoul National University, Gwanak-gu, Seoul 08826, Korea; yjko@snu.ac.kr \\ * Correspondence: khkim83@skku.edu; Tel.: +82-31-290-7700
}

Received: 30 October 2019; Accepted: 19 November 2019; Published: 20 November 2019

\begin{abstract}
Withania somnifera (L.) Dunal (Solanaceae), known as Indian ginseng or ashwagandha, has been used in Indian Ayurveda for the treatment of a variety of disorders, such as diabetes and reproductive and nervous system disorders. It is particularly used as a general health tonic, analgesic, and sedative. As part of continuing projects to discover unique bioactive natural products from medicinal plants, phytochemical investigation of the roots of $W$. somnifera combined with a liquid chromatography-mass spectrometry (LC/MS)-based analysis has led to the isolation of two novel phenylpropanoid esters, Withaninsams A (1) and B (2), as an inseparable mixture, along with three known phenolic compounds $(3,4$, and 6$)$ and a pyrazole alkaloid (5). The structures of the new compounds were elucidated using a combination of spectroscopic methods, including one-dimensional (1D) and two-dimensional (2D) nuclear magnetic resonance (NMR) and high-resolution electrospray ionization mass spectroscopy (HR-ESIMS). Withaninsams A (1) and B (2) are phenylpropanoid esters that contain a side chain, 4-methyl-1,4-pentanediol unit. To the best of our knowledge, the present study is the first to report on phenylpropanoid esters with 4-methyl-1,4-pentanediol unit. The anti-inflammatory activity of the isolated compounds (1-6) was evaluated by determining their inhibitory effects on nitric oxide (NO) production in lipopolysaccharide (LPS)-stimulated RAW 264.7 macrophages, where compound 3 inhibited LPS-induced NO production $\left(\mathrm{IC}_{50}=33.3 \mu \mathrm{M}\right)$ and TNF- $\alpha$ production, a pro-inflammatory cytokine $\left(\mathrm{IC}_{50}=40.9 \mu \mathrm{M}\right)$. The anti-inflammatory mechanism through the inhibition of transcriptional iNOS protein expression was confirmed by western blotting experiments for the active compound 3, which showed decreased iNOS protein expression.
\end{abstract}

Keywords: Withania somnifera; phenylpropanoid esters; Withaninsams A and B; nitric oxide; inducible nitric oxide synthase

\section{Introduction}

Withania somnifera (L.) Dunal (Solanaceae), commonly known as Indian ginseng or ashwagandha, is a perennial shrub distributed in India, Morocco, Egypt, Israel, Jordan, South Africa, and the Mediterranean region. Currently, it is cultivated on a small scale in South Korea as well [1-3]. This plant has been used in Indian Ayurveda for over 3000 years for the treatment of a variety of disorders, such as diabetes and nervous and reproductive disorders. It is particularly used as a general health tonic, analgesic, and sedative [4]. The name, Indian ginseng is botanically not related to Korean ginseng (Panax ginseng). The similarity in the name arises from its similar bioactivity [5]. Roots of W. somnifera 
have recently gained popularity as a functional food that promotes longevity through delaying aging, increasing immunity against extrinsic factors, and strengthening the body $[1,6]$. In practice, extracts of the roots are consumed in several forms, such as powder, liquid, tablets, and capsules. Moreover, roots are consumed as a dietary supplement.

Previous pharmacological studies on $W$. somnifera have revealed that extracts of $W$. somnifera exhibit a protective role against bromobenzene-induced oxidative damage in the rat liver [7], as well as increase the exercise performance [8]. Similarly, a recent study on $W$. somnifera extracts reported its therapeutic role in stroke repair through its anti-apoptotic and anti-oxidant properties [9]. Chemically, it is a rich source of withanolides, which possess diverse pharmacological properties, including anti-inflammatory, anti-microbial, anti-tumor, hepatoprotective, and immunosuppressive effects [10-16]. In addition, alkaloids, steroidal saponins, lignanamides [17], and phenolics [18] have also been reported, and some of them were found to have anti-tumor activities [19].

As part of a continuing program to determine structurally and/or biologically novel natural products from medicinal plants [20-23], we conducted a chemical investigation of the methanol $(\mathrm{MeOH})$ extract of roots of $W$. somnifera. In our recent study, chemical analysis of the $\mathrm{MeOH}$ extract, combined with a liquid chromatography/mass spectroscopy (LC/MS)-based analysis, we identified six new withanolides, namely withasilolides A to F, and seven known withanolides [3], some of which exhibited cytotoxicity against several human cancer cell lines (A549, SK-OV-3, SK-MEL-2, and HCT-15). In the present study, we focused on other constituents of $W$. somnifera rather than withanolides. The phytochemical analysis of the $\mathrm{MeOH}$ extract led to the isolation of two new phenylpropanoid esters (1 and 2) as an inseparable mixture, along with four known compounds (3-6) (Figure 1). The structures of the new compounds ( $\mathbf{1}$ and $\mathbf{2}$ ) were elucidated using a combination of one-dimensional (1D) and two-dimensional (2D) nuclear magnetic resonance (NMR) spectroscopy and high-resolution electrospray ionization mass spectroscopy (HR-ESIMS) data. Further, we evaluated the inhibitory effects of the isolates on nitric oxide (NO) production in lipopolysaccharide (LPS)-activated RAW 264.7 macrophages. In the present study, we describe the isolation and structural characterization of isolated compounds, as well as the evaluation of their NO inhibitory effects on LPS-activated RAW264.7 macrophages.<smiles>COc1cc(/C=C/C(=O)OCCCC(C)(C)C)ccc1O</smiles>

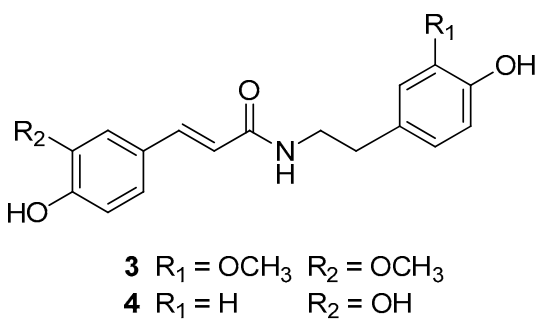<smiles>COc1cc(/C=C\C(=O)OCCCC(C)(C)O)ccc1O</smiles>

2

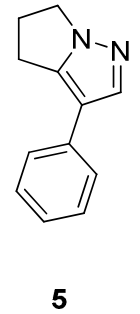<smiles>COc1cc(C(C)=O)cc(OC)c1O</smiles>

6

Figure 1. Chemical structures of compounds 1-6.

\section{Results and Discussion}

\subsection{Isolation of Compounds}

The dried roots of $W$. somnifera were extracted with $80 \% \mathrm{MeOH}$ under reflux to yield the methanol extract, which was sequentially applied to solvent-partitioning with hexane, dichloromethane, ethyl acetate, and $n$-butanol to obtain each solvent fraction. Chemical analysis of hexane-soluble and dichloromethane-soluble fractions was performed using repeated column chromatography and 
high-performance liquid chromatography (HPLC) along with LC/MS-based analysis. These techniques were combined with our house-built UV library to determine other types of minor constituents, rather than withanolides. The analysis led to the isolation of two new phenylpropanoid esters (1 and 2$)$ as an inseparable mixture, along with three known phenolic compounds $(3,4$, and 6$)$ and a pyrazole alkaloid (5) (Figure 1). The novel compounds resulted in only one peak in HPLC performed using Phenomenex Luna C18 column (MeOH/ $\mathrm{H}_{2} \mathrm{O}, 7: 3$ to $\left.1: 0\right)$.

\subsection{Structure Elucidation of Compounds}

Compounds 1 and $\mathbf{2}$ were obtained as a trans/cis inseparable mixture in the ratio of approximately 5:4 (as calculated from the ${ }^{1} \mathrm{H}$ NMR integral). They were isolated as an amorphous powder, and their HR-ESIMS (Figure S1) showed the molecular ion peak [M + Na] ${ }^{+}$at $\mathrm{m} / \mathrm{z} 317.1375$ (calculated for $\mathrm{C}_{16} \mathrm{H}_{22} \mathrm{O}_{5} \mathrm{Na}$, 317.1365) in the positive mode, compatible with the molecular formula of $\mathrm{C}_{16} \mathrm{H}_{22} \mathrm{O}_{5}$. The IR spectrum exhibited characteristic absorptions of hydroxy $\left(3305 \mathrm{~cm}^{-1}\right)$ and ester groups $\left(1755 \mathrm{~cm}^{-1}\right)$. The ${ }^{1} \mathrm{H}$ NMR spectrum (Table 1, Figure S2) showed complicated aromatic proton signals in the narrow region between $\delta_{\mathrm{H}} 6.77$ and 7.08. Most of the ${ }^{13} \mathrm{C}$ NMR signals, which were assigned by ${ }^{1} \mathrm{H}^{-1} \mathrm{H}$ correlation spectroscopy (COSY) (Figure S3), heteronuclear single quantum coherence (HSQC) (Figure S4), and heteronuclear multiple bond correlation (HMBC) (Figure S5) experiments, were split into pairs of narrowly separated signals (Table 1). Based on the assigned molecular formula $\left(\mathrm{C}_{16} \mathrm{H}_{22} \mathrm{O}_{5}\right)$ by HR-ESIMS, we deduced that the two compounds could be a mixture of two closely related compounds, 1 and 2 . The detailed inspection of the ${ }^{1} \mathrm{H}$ NMR spectrum (Table 1 ) revealed the presence of two sets of 1,3,4-trisubstituted aromatic protons, one at $\delta_{\mathrm{H}} 6.89(1 \mathrm{H}, \mathrm{d}, J=8.0 \mathrm{~Hz}), 7.01$ $(1 \mathrm{H}, \mathrm{d}, J=1.5 \mathrm{~Hz})$, and $7.05(1 \mathrm{H}, \mathrm{dd}, J=8.0,1.5 \mathrm{~Hz})$ and another at $\delta_{\mathrm{H}} 6.86(1 \mathrm{H}, \mathrm{d}, J=8.0 \mathrm{~Hz}), 7.08$ $(1 \mathrm{H}, \mathrm{dd}, J=8.0,2.0 \mathrm{~Hz})$, and $7.74(1 \mathrm{H}, \mathrm{d}, J=2.0 \mathrm{~Hz})$, as well as two methoxy groups at $\delta_{\mathrm{H}} 3.91(6 \mathrm{H}$, $\mathrm{s})$. Interpretation of the ${ }^{1} \mathrm{H}$ NMR and ${ }^{1} \mathrm{H}-{ }^{1} \mathrm{H}$ COSY spectra (Figure S3) led to the following structural units: C-5 to C-6 and C-7 to C-8 (Figure 2). Connectivities of the partial structure of phenylpropanoid were established on the HMBC cross-peaks of H-2/C-4, C-6, H-5/C-1, C-3, H-6/C-2, C-4, H-7/C-2, C-6, C-9, and H-8/C-1, C-9 (Figure 2). The HMBC correlation of the methoxy group $\left(\delta_{\mathrm{H}} 3.91\right) / C-3$ provided evidence of the presence of the methoxy group at C-3. The presence of 4-methyl-1,4-pentanediol was established on the HMBC cross-peaks of H-1'/C-3', H-3'/C-1', C-5', C-6', H-5'/C-3', C-6', and H-6'/C-3', $\mathrm{C}-5^{\prime}$, together with ${ }^{1} \mathrm{H}-{ }^{1} \mathrm{H}$ COSY correlations from $\mathrm{H}-1^{\prime}$ to $\mathrm{H}-3^{\prime}$ (Figure 2). The linkage between the phenylpropanoid and 4-methyl-1,4-pentanediol unit was established using the HMBC correlation from H-1' to C-9 (Figure 2).

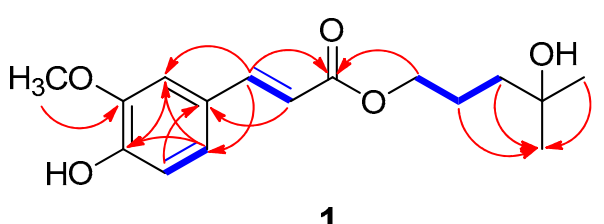

1

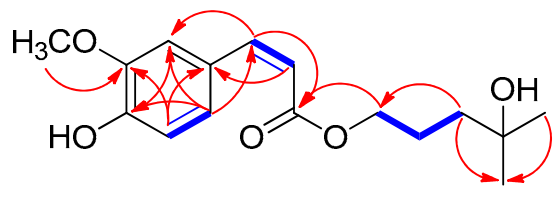

2

Figure 2. ${ }^{1} \mathrm{H}-{ }^{1} \mathrm{H}$ correlation spectroscopy $(\mathrm{COSY})(-)$ and key heteronuclear multiple bond correlation $(\mathrm{HMBC})(\frown)$ correlations for compounds 1 and 2.

The geometry of the di-substituted olefin $\Delta^{7 / 8}$ in compounds $\mathbf{1}$ and $\mathbf{2}$ was determined on the basis of the vicinal ${ }^{1} \mathrm{H}$ coupling constant $\left(J_{7,8}=16.0 \mathrm{~Hz}\right.$ in $1 ; J_{7,8}=13.0 \mathrm{~Hz}$ in 2$)$ [24], which indicated that compound 1 had trans-conformation, whereas compound 2 had cis-conformation. Moreover, this assignment is supported by the typical NMR chemical shifts exhibiting $\delta_{\mathrm{H}} 6.27(\mathrm{H}-8)$ and $\delta_{\mathrm{H}} 7.58(\mathrm{H}-7)$ in compound 1 (trans) and $\delta_{\mathrm{H}} 5.79(\mathrm{H}-8)$ and $\delta_{\mathrm{H}} 6.77(\mathrm{H}-7)$ in compound 2 (cis) [24]. Therefore, structures of compounds 1 and $\mathbf{2}$ were determined as shown in Figure 1, with their trivial names designated as Withaninsams A (1) and B (2), respectively. Withaninsams A (1) and B (2) are phenylpropanoid esters containing a side chain, 4-methyl-1,4-pentanediol unit, which is a rare example of a natural product. Although phenylpropanoid esters with similar side chains, such as tert-butyl trans-ferulate and tert-butyl 
(2E)-3-(3,4-dimethoxyphenyl)-2-propenoate, have been reported [25,26], to the best of our knowledge, the present study is the first to report on phenylpropanoid esters with 4-methyl-1,4-pentanediol unit. Finally, we attempted to separate the mixture of $\mathbf{1}$ and $\mathbf{2}$ using the chiral HPLC column, Phenomenex Lux Cellulose-1; however, we failed to resolve the mixture into a pair of pure enantiomers under different conditions.

Table 1. ${ }^{1} \mathrm{H}$ and ${ }^{13} \mathrm{C}$ NMR data of compounds 1 and 2 in $\mathrm{CD}_{3} \mathrm{OD}\left(\delta\right.$ in ppm, $800 \mathrm{MHz}$ for ${ }^{1} \mathrm{H}$ and $200 \mathrm{MHz}$ for $\left.{ }^{13} \mathrm{C}\right)^{\mathrm{a}}$.

\begin{tabular}{|c|c|c|c|c|}
\hline \multirow[t]{2}{*}{ Position } & \multicolumn{2}{|c|}{1} & \multicolumn{2}{|c|}{2} \\
\hline & $\delta_{\mathrm{H}}$ & $\delta_{\mathrm{C}}$ & $\delta_{H}$ & $\delta_{\mathrm{C}}$ \\
\hline 1 & & 127.0 & & 127.3 \\
\hline 2 & $7.01 \mathrm{~d}(1.5)$ & 109.2 & $7.74 \mathrm{~d}(2.0)$ & 112.6 \\
\hline 3 & & 146.5 & & 145.9 \\
\hline 4 & & 147.9 & & 147.0 \\
\hline 5 & $6.89 \mathrm{~d}(8.0)$ & 114.6 & $6.86 \mathrm{~d}(8.0)$ & 113.7 \\
\hline 6 & $7.05 \mathrm{dd}(1.5,8.0)$ & 123.1 & $7.08 \mathrm{dd}(2.0,8.0)$ & 125.5 \\
\hline 7 & $7.58 \mathrm{~d}(16.0)$ & 114.6 & $6.77 \mathrm{~d}(13.0)$ & 143.7 \\
\hline 8 & $6.27 \mathrm{~d}(16.0)$ & 115.6 & $5.79 \mathrm{~d}(13.0)$ & 116.8 \\
\hline 9 & & 167.3 & & 166.7 \\
\hline $1^{\prime}$ & $4.16 \mathrm{t}(7.0)$ & 64.4 & $4.09 \mathrm{t}(7.0)$ & 64.4 \\
\hline $2^{\prime}$ & $1.37 \mathrm{~m}$ & 28.6 & $1.30 \mathrm{~m}$ & 28.5 \\
\hline $3^{\prime}$ & $1.67 \mathrm{~m}$ & 25.9 & $1.62 \mathrm{~m}$ & 25.8 \\
\hline $4^{\prime}$ & & n.d. ${ }^{\mathrm{b}}$ & & n.d. ${ }^{b}$ \\
\hline $5^{\prime}$ & $1.23 \mathrm{~s}$ & 29.5 & $1.23 \mathrm{~s}$ & 29.5 \\
\hline $6^{\prime}$ & $1.23 \mathrm{~s}$ & 29.5 & $1.23 \mathrm{~s}$ & 29.5 \\
\hline$-\mathrm{OCH}_{3}$ & $3.91 \mathrm{~s}$ & 55.6 & $3.91 \mathrm{~s}$ & 55.6 \\
\hline
\end{tabular}

a $J$ values are in parentheses and reported in $\mathrm{Hz} ;{ }^{13} \mathrm{C}$ NMR assignments are based on ${ }^{1} \mathrm{H}-{ }^{1} \mathrm{H} C O S Y, \mathrm{HSQC}$, and HMBC experiments; ${ }^{b}$ not detected.

The known compounds were identified as N-trans-feruloyl methoxytyramine (3) [27], $\mathrm{N}$-trans-feruloyltyramine (4) [28], withasomnine (5) [29], and acetosyringone (6) [30] by comparing their NMR spectroscopic data with reported values as well as using the LC/MS analysis results.

\subsection{Inhibitory Effects of Compounds 1-6 on LPS-Induced NO Production in RAW 264.7 Cells}

To determine whether the isolated compounds $\mathbf{1}$ to $\mathbf{6}$ had anti-inflammatory properties, we performed NO assay using supernatants from LPS-stimulated RAW 264.7 cells. All compounds tested exhibited no cytotoxicity up to each highest concentration (Figure 3A). Of these, compound 3 exhibited an inhibitory effect on NO production in LPS-stimulated RAW 264.7 cells $\left(\mathrm{IC}_{50}=33.3 \mu \mathrm{M}\right)$ (Figure 3B). The effect of compound 3 on the LPS-induced TNF- $\alpha$ production showed similar patterns to those of NO production $\left(\mathrm{IC}_{50}=40.9 \mu \mathrm{M}\right)$ (Figure $3 \mathrm{C}$ ). To confirm whether NO inhibitory effect of 3 was related to reduced expression of nitric oxide synthase (iNOS), enzyme involved in the synthesis of NO, we evaluated the effect of compound 3 on iNOS expression. Similar to the results of NO production, compound 3 reduced iNOS expression in LPS-stimulated RAW 264.7 cells (Figure 4). These results indicated that compound 3 exerted anti-inflammatory effect on macrophages by reducing LPS-induced NO production through transcriptional inhibition of iNOS. 

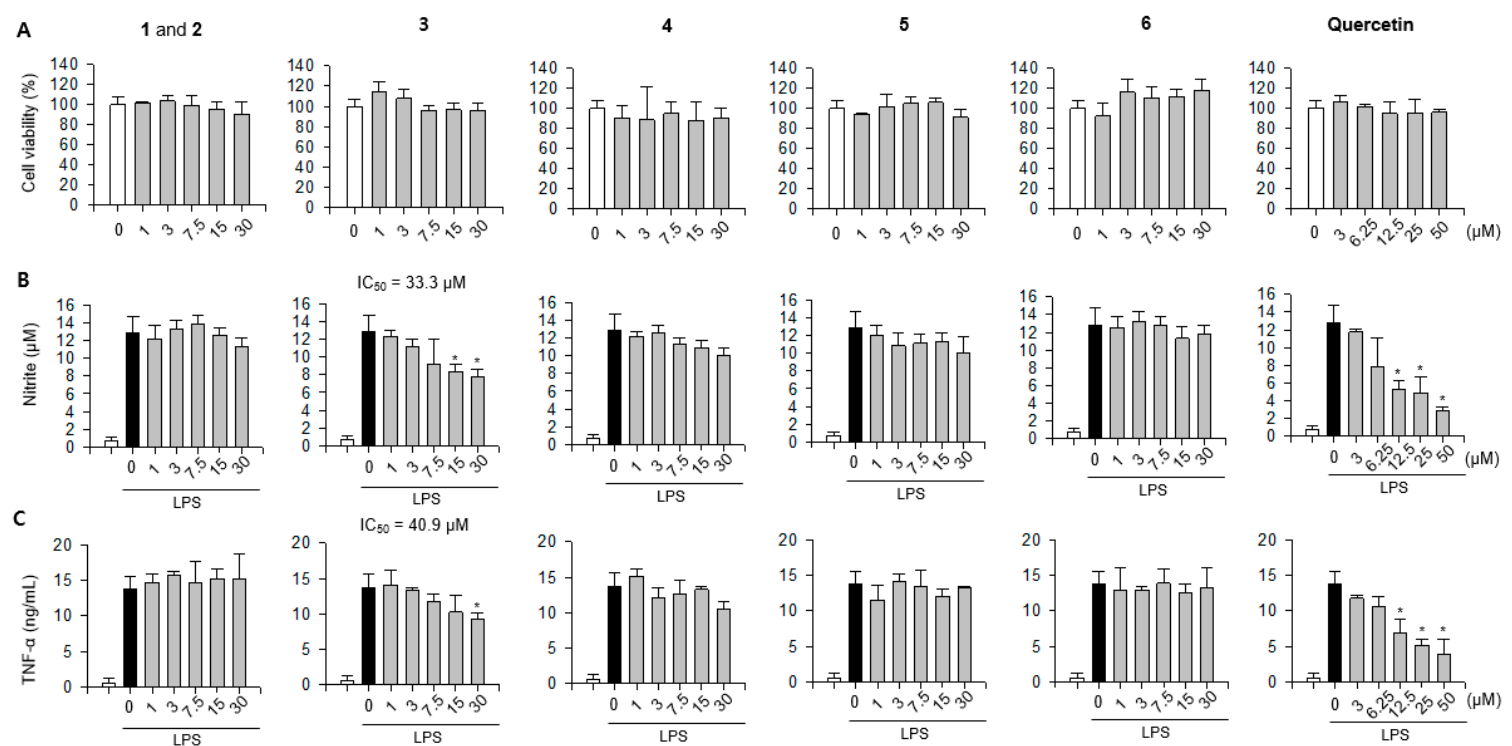

Figure 3. Inhibitory effects of compounds 1-6 on the production of pro-inflammatory mediators in macrophages. RAW 264.7 cells were treated with compounds 1-6 in the absence or presence of lipopolysaccharide (LPS) and then (A) cell viability, (B) nitric oxide (NO) production, and (C) TNF- $\alpha$ production in RAW 264.7 cells were determined. Quercetin was used as a positive control. (A) Cell viability data represent relative cell viability compared with that of the untreated group $(100 \%$, white bar). (B,C) NO and TNF- $\alpha$ production data represent actual production levels calculated by applying absorbance values to each standard curve. (white bar, untreated control group; grey and black bar, LPS-treated control group). $p<0.05$ relative to the LPS-treated control group.

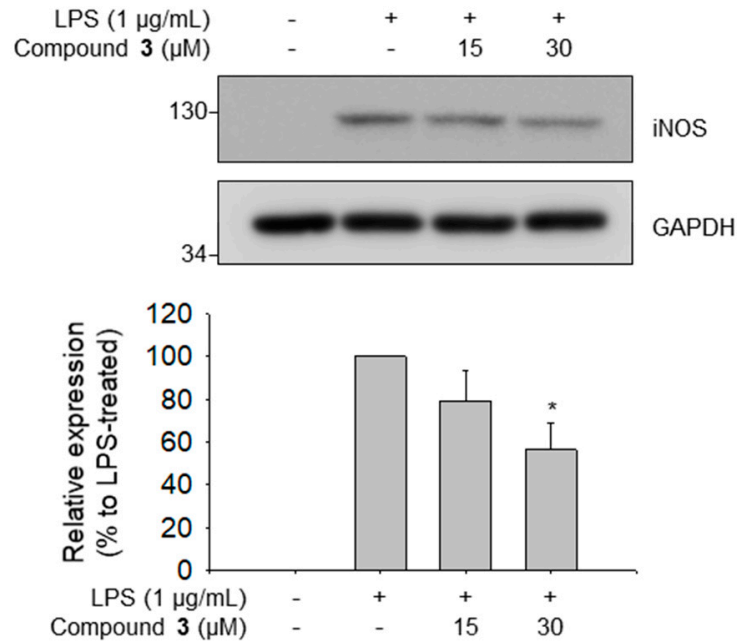

Figure 4. Inhibitory effect of compound 3 on LPS-induced nitric oxide synthase (iNOS) expression in RAW 264.7 cells. Data represent relative iNOS protein expression levels compared with those in the LPS-treated group (100\%). $p<0.05$ relative to the LPS-treated control group.

\section{Materials and Methods}

\subsection{Plant Material}

The roots of $W$. somnifera were purchased from Seonggeosan Farm, Cheonan, Korea, in October 2016, and the plant was identified by one of the authors (K.H.K.). A voucher specimen of the material (IDG-2016) was deposited in the herbarium of the School of Pharmacy, Sungkyunkwan University, Suwon, Republic of Korea. 


\subsection{Extraction and Isolation}

Dried roots of $W$. somnifera $(1.3 \mathrm{~kg}$ ) were extracted with $80 \%$ aqueous $\mathrm{MeOH}$ (each $3.0 \mathrm{~L} \times 3$ days) under reflux and filtered. The filtrate was combined and concentrated under vacuum using a rotary evaporator to obtain a $\mathrm{MeOH}$ extract (189.6 g). The extract was suspended in distilled water $(700 \mathrm{~mL})$ and successively solvent-partitioned using hexane, dichloromethane $\left(\mathrm{CH}_{2} \mathrm{Cl}_{2}\right)$, ethyl acetate (EtOAc), and $n$-butanol $(n$-BuOH). Four fractions with increasing polarity were obtained: hexane-soluble ( $3.4 \mathrm{~g})$, $\mathrm{CH}_{2} \mathrm{Cl}_{2}$-soluble ( $\left.4.5 \mathrm{~g}\right)$, EtOAc-soluble $(2.0 \mathrm{~g})$, and $n$-BuOH-soluble $(18.6 \mathrm{~g})$. The hexane-soluble fraction $(3.2 \mathrm{~g})$ was fractionated using silica gel column chromatography with a gradient solvent system of hexane/EtOAc (20:1 to 1:1). The column was washed with $\mathrm{CH}_{2} \mathrm{Cl}_{2} / \mathrm{MeOH}$ (1:1) to obtain seven hexane fractions (H1-H7). Fraction H6 (300.1 mg) was separated by preparative reversed-phase HPLC using an Agilent Eclipse $\mathrm{C}_{18}$ column with gradient solvent system $\mathrm{MeOH} / \mathrm{H}_{2} \mathrm{O}$ (7:3 to 1:0) to obtain seven subfractions (H6a-H6g). Subfraction H6c (134.6 mg) was purified by semi-preparative HPLC (38\% $\mathrm{MeCN}$ ) on Phenomenex Luna C18 column to yield compound 5 (24.3 mg). Subfraction H6g (22.9 mg) was purified by semi-preparative HPLC with gradient solvent system $\mathrm{MeOH} / \mathrm{H}_{2} \mathrm{O}$ (7:3 to 1:0) on Phenomenex Luna C18 column to yield a mixture of compounds 1 and $\mathbf{2}(1.1 \mathrm{mg})$. The $\mathrm{CH}_{2} \mathrm{Cl}_{2}$-soluble fraction $(4.5 \mathrm{~g})$ was fractionated using silica gel column chromatography with gradient solvent system of $\mathrm{CH}_{2} \mathrm{Cl}_{2} / \mathrm{MeOH}$ (50:1 to 1:1) to obtain seven fractions (C1-C7). Fraction $\mathrm{C} 1$ (73.6 mg) was separated by preparative reversed-phase HPLC on an Agilent Eclipse $C_{18}$ column with gradient solvent system $\mathrm{MeOH} / \mathrm{H}_{2} \mathrm{O}$ (3:7 to 1:0) to obtain five subfractions (C1a-C1e). Subfraction C1c (11.8 mg) was purified using semi-preparative HPLC ( $33 \% \mathrm{MeOH})$ on Phenomenex Luna C18 column to yield compound 6 (7.2 mg). Fraction C3 (401.6 mg) was fractionated using preparative reversed-phase HPLC on Agilent Eclipse $\mathrm{C}_{18}$ column with gradient solvent system $\mathrm{MeOH} / \mathrm{H}_{2} \mathrm{O}$ (3:7 to 1:0) to obtain six subfractions (C3a-C3f). Subfraction C3d (33.8 mg) was purified using semi-preparative HPLC on Phenomenex Luna C18 column ( $47 \% \mathrm{MeOH})$ to yield compound $3(2.4 \mathrm{mg})$. Fraction C4 (166.0 mg) was separated by reversed-phase preparative HPLC using an Agilent Eclipse $\mathrm{C}_{18}$ column with gradient solvent system $\mathrm{MeOH} / \mathrm{H}_{2} \mathrm{O}$ (4:6 to 9:1) to obtain six subfractions (C4a-C4f). Subfraction $\mathrm{C} 4 \mathrm{c}(19.2 \mathrm{mg})$ was purified by semi-preparative HPLC (40\% MeOH) on Phenomenex Luna C18 column to yield compound 4 (3.3 mg).

Withaninsams A (1) and B (2)

White, amorphous powder; ESIMS (positive mode) $m / z: 317[\mathrm{M}+\mathrm{Na}]^{+} ;$HRESIMS (positive mode) $m / z: 317.1375[\mathrm{M}+\mathrm{Na}]^{+}$, calcd for $\mathrm{C}_{16} \mathrm{H}_{22} \mathrm{O}_{5} \mathrm{Na}, 317.1365 ; \mathrm{UV}(\mathrm{MeOH}) \lambda_{\max } \mathrm{nm}(\log \varepsilon): 220$ (2.29), 240 (2.10), 290 (2.54), 325 (3.42); IR (KBr) $v_{\max } \mathrm{cm}^{-1}: 3305,3126,1755,1585,1492,1042 ;{ }^{1} \mathrm{H}\left(\mathrm{CD}_{3} \mathrm{OD}\right.$, $800 \mathrm{MHz})$ and ${ }^{13} \mathrm{C}\left(\mathrm{CD}_{3} \mathrm{OD}, 200 \mathrm{MHz}\right)$ NMR spectroscopic data, see Table 1.

\subsection{Cell Viability Assay}

RAW 264.7 cells $\left(6.0 \times 10^{4}\right.$ cells/well) were seeded into a 96-well plate and incubated overnight for adhesion. Following incubation, the cells were treated with compounds for $24 \mathrm{~h}$. Next, Ez-CytoX solution (1/10 volume of the culture medium, Daeil Lab., Seoul, Korea) was added to each well and cells were further incubated for $1 \mathrm{~h}$. The cell viability was assessed by measuring the absorbance at $450 \mathrm{~nm}$.

\subsection{NO Production Assay}

RAW 264.7 cells $\left(6.0 \times 10^{4}\right.$ cells/well $)$ were seeded into a 96-well plate and incubated overnight for adhesion. Following incubation, the cells were treated with compounds and LPS. After $24 \mathrm{~h}$ incubation, supernatants were collected and treated with Griess reagent for evaluating NO concentration in the reactants. The absorbance was measured at $540 \mathrm{~nm}$ and NO production was calculated by referring to the nitrite standard curve. 


\subsection{TNF- $\alpha$ ELISA}

Culture supernatants were applied to ELISA experiments for measuring the production of TNF- $\alpha$ in LPS-stimulated RAW 264.7 cells. ELISA was performed by manufacturer's instructions (Ebioscience, San Diego, CA, USA). Each step was followed by washing with $1 \times$ PBST 5 times. Briefly, plate was coated with coating antibody solution overnight at $4{ }^{\circ} \mathrm{C}$ and then blocked with $1 \times$ assay diluent for $1 \mathrm{~h}$ at room temperature (RT). Supernatants were applied to the plate for $2 \mathrm{~h}$ at $\mathrm{RT}$ and the plate was incubated with biotinylated secondary antibody for $1 \mathrm{~h}$ at RT. After reacting the plate with horseradish peroxidase (HRP)-streptavidin for $40 \mathrm{~min}$ at $\mathrm{RT}$, the plate was reacted with 4-nitrophenyl phosphate disodium salt in diethanolamine buffer as a substrate for $10 \mathrm{~min}$ at dark condition and the reaction was stopped by adding $1 \mathrm{~N} \mathrm{NaOH}$. Absorbances of each well at $405 \mathrm{~nm}$ were applied to standard curve for calculating the quantity of TNF- $\alpha$ at supernatants.

\subsection{Western Blotting}

RAW 264.7 cells $\left(2.0 \times 10^{5}\right.$ cells/well $)$ were seeded into 6-well plates and incubated overnight for adhesion. Following incubation, the cells were treated with compounds 3 and 4 in the presence of LPS for $24 \mathrm{~h}$. Total cell lysates were obtained and loaded onto sodium dodecyl sulfate-polyacrylamide gel electrophoresis (SDS-PAGE). Proteins were subsequently transferred onto nitrocellulose (NC) membrane. Membranes were incubated with primary antibodies against iNOS and GAPDH, following which the membranes were incubated with appropriate secondary antibodies. Finally, the membranes were blotted and protein band intensities were analyzed using Imager 680 (GE Healthcare; Chicago, IL, USA).

\subsection{Statistical Analysis}

The data were statistically analyzed using Student's $t$-test. To prove statistical significance, experiments were conducted in replicates as follows: nine for cell viability, NO assay, TNF- $\alpha$ ELISA and three for western blotting. A $p$-value $<0.05$ was considered statistically significant.

\section{Conclusions}

In the present study, phytochemical analysis of the $\mathrm{MeOH}$ extracts of roots of W. somnifera led to the isolation of two novel phenylpropanoid esters, namely Withaninsams A (1) and B (2) as an inseparable mixture, along with three known phenolic compounds $(3,4$, and $\mathbf{6})$ and a pyrazole alkaloid (5). Withaninsams A (1) and B (2) are phenylpropanoid esters that contain a side chain, 4-methyl-1,4-pentanediol unit. To the best of our knowledge, the present study is the first to report on phenylpropanoid esters with 4-methyl-1,4-pentanediol unit. All isolated compounds were evaluated for their anti-inflammatory effects on nitric oxide (NO) production in LPS-stimulated RAW 264.7 macrophages. Compound 3 exhibited NO and TNF- $\alpha$ inhibitory properties without cytotoxicity. The active compound 3 inhibited NO production by reducing iNOS protein expression.

Supplementary Materials: The following are available online at http://www.mdpi.com/2223-7747/8/12/527/s1, Figure S1: The HRESIMS data of compounds $\mathbf{1}$ and 2, Figure S2: The ${ }^{1} \mathrm{H}$ NMR spectrum of compounds $\mathbf{1}$ and 2, Figure S3: The ${ }^{1} \mathrm{H}^{-1} \mathrm{H}$ COSY spectrum of compounds 1 and 2, Figure S4: The HSQC spectrum of compounds 1 and 2, Figure S5: The HMBC spectrum of compounds 1 and 2.

Author Contributions: Conceptualization, Y.-C.C. and K.H.K.; formal analysis, S.C.B., S.L., S.K., Y.-J.K., and M.S.J.; investigation, S.C.B., S.L., S.K., M.S.J., J.S.Y., and Y.-C.C.; writing —original draft preparation, S.C.B., Y.-C.C., and K.H.K.; writing - review and editing, S.C.B. and K.H.K.; supervision, K.H.K.; project administration, Y.-C.C. and K.H.K.; funding acquisition, K.H.K.

Funding: This work was supported by a National Research Foundation of Korea (NRF) grant funded by the Korean government (MSIT) (2018R1A2B2006879 and 2019R1A5A2027340).

Conflicts of Interest: The authors declare no conflict of interest. 


\section{References}

1. Khare, C.P. Encyclopedia of Indian Medicinal Plants; Springer Verlag: New York, NY, USA, 2004; pp. 480-483.

2. Gupta, G.L.; Rana, A.C. Withaniasomnifera (Ashwagandha): A review. Pharmacogn. Rev. 2007, 1, $129-136$.

3. Kim, S.; Yu, J.S.; Lee, J.Y.; Choi, S.U.; Lee, J.; Kim, K.H. Cytotoxic Withanoildes from the Roots of Indian Ginseng (Withaniasomnifera). J. Nat. Prod. 2019, 82, 765-773. [CrossRef] [PubMed]

4. Kulkarni, S.K.; Dhir, A. Withaniasomnifera: An Indian ginseng. Prog. Neuro-Psychopharmacol. Biol. Psychiatry 2008, 32, 1093-1105. [CrossRef] [PubMed]

5. Singh, B.; Saxena, A.K.; Chandan, B.K.; Gupta, D.K.; Bhutani, K.K.; Anand, K.K. Adaptogenic activity of novel, withanolide-free aqueous fraction from the roots of Withaniasomnifera Dun. Phytother. Res. 2001, 15, 311-318. [CrossRef] [PubMed]

6. Weiner, M.A.; Weiner, J. Herbs That Heal: Prescription for Herbal Healing; Atrium Publishers Group: Mill Valley, CA, USA, 1994; p. 70.

7. Vedi, M.; Rasool, M.; Sabina, E.P. Amelioration of bromobenzene hepatotoxicity by Withaniasomnifera pretreatment: Role of mitochondrial oxidative stress. Toxicol. Rep. 2014, 1, 629-638. [CrossRef] [PubMed]

8. Ziegenfuss, T.N.; Kedia, A.W.; Sandrock, J.E.; Raub, B.J.; Kerksick, C.M.; Lopez, H.L. Effects of an Aqueous Extract if Withaniasomnifera on Strength Training Adaptations and Recovery: The STAR Trial. Nurtrients 2018, 10, 1807. [CrossRef]

9. Raghavan, A.; Shah, Z.A. Withaniasomnifera Improves Ischemic Stroke Outcomes by Attenuating PARP1-AIF-Mediated Caspase-Independent Apoptosis. Mol. Neurobiol. 2015, 52, 1093-1105. [CrossRef]

10. Ma, T.; Zhang, W.-N.; Yang, L.; Zhang, C.; Lin, R.; Shan, S.-M.; Zhu, M.-D.; Luo, J.-G.; Kong, L.-Y. Cytotoxic withanolides from Physalis angulata var. villosa and the apoptosis-inducing effect via ROS generation and the activation of MAPK in human osteosarcoma cells. RSC Adv. 2016, 6, 53089-53100. [CrossRef]

11. Habtemariam, S. Cytotoxicity and Immunosuppressive Activity of Withanoliedes from Discopodiumpenninervium. Planta Med. 1997, 63, 15-17. [CrossRef]

12. Budhiraja, R.D.; Sudhir, S.; Garg, K.N. Antiinflmmatory Activity of $3 \beta$-Hydroxy-2,3-dihydro-withanolide F. Planta Med. 1984, 50, 134-136. [CrossRef]

13. Chakraborti, S.K.; De Barun, K.; Bandyopadhyay, T. Variations in the antitumor constituents of Withaniasomnifera dunal. Experientia 1974, 30, 852-853. [CrossRef] [PubMed]

14. Mareggiani, G.; Picollo, M.I.; Zerba, E.; Burton, G.; Tettamanzi, M.C.; Benedetti-Doctorovich, M.O.V.; Veleiro, A.S. Antifeedant Activity of Withanolides from Salpichroaoriganifolia on Musca Domestica. J. Nat. Prod. 2000, 63, 1113-1116. [CrossRef] [PubMed]

15. Basso, A.V.; Leiva Gonzalez, S.; Barboza, G.E.; Careaga, V.P.; Calvo, J.C.; Sacca, P.A.; Nicotra, V.E. Phytochemical Study of the Genus Salpichroa (Solanaceae), Chemotaxonomic Considerations, and Biological Evaluation in Prostate and Breast Cancer Cells. Chem. Biodivers. 2017, 14, e1700118. [CrossRef]

16. Zhang, H.; Cao, C.-M.; Gallagher, R.J.; Timmermann, B.N. Antiproliferative withanolides from several solanaceous spicies. Nat. Prod. Res. 2014, 28, 1941-1951. [CrossRef]

17. Bolleddula, J.; Fitch, W.; Vareed, S.K.; Nair, M.G. Identification of metabolies in Withaniasomnifera fruits by liquid chromatography and high-resolution mass spectrometry. Rapid Commun. Mass Spectrom. 2012, 26, 1277-1290. [CrossRef]

18. Elsakka, M.; Grigorescu, E.; Stănescu, U.; Dorneanu, V. New data referring to chemistry of Withaniasomnifera species. Rev. Med. Chir. Soc. Med. Nat. IASI 1990, 94, 385-387.

19. Jayaprakasam, B.; Zhang, Y.; Seeram, N.P.; Nair, M.G. Growth inhibition of human tumor cell lines by withanolides from Withaniasomnifera leaves. Life Sci. 2003, 74, 125-132. [CrossRef]

20. So, H.M.; Eom, H.J.; Lee, D.; Kim, S.; Kang, K.S.; Lee, I.K.; Baek, K.-H.; Park, J.Y.; Kim, K.H. Bioactivity evaluations of betulin identified from the bark of Betula platyphylla var. japonica for cancer therapy. Arch. Pharm. Res. 2018, 41, 815-822. [CrossRef]

21. Yu, J.S.; Roh, H.-S.; Baek, K.-H.; Lee, S.; Kim, S.; So, H.M.; Moon, E.; Pang, C.; Jang, T.S.; Kim, K.H. Bioactivity-guided isolation of ginsenosides from Korean Red Ginsengwith cytotoxic activity against human lung adenocarcinoma cells. J. Ginseng Res. 2018, 42, 562-570. [CrossRef]

22. Baek, S.C.; Choi, E.; Eom, H.J.; Jo, M.S.; Kim, S.; So, H.M.; Kim, S.H.; Kang, K.S.; Kim, K.H. LC/MS-based analysis of bioactive compounds from the bark of Betula platyphylla var. japonica and their effects on regulation of adipocyte and osteoblast differentiation. Nat. Prod. Sci. 2018, 24, 235-240. [CrossRef] 
23. Yu, J.S.; Lee, D.; Lee, S.R.; Lee, J.W.; Choi, C.-I.; Jang, T.S.; Kang, K.S.; Kim, K.H. Chemical characterization of cytotoxic indole acetic acid derivative from Mulberry fruit (Morus alba L.) against human cervical cancer. Bioorg. Chem. 2018, 76, 28-36. [CrossRef] [PubMed]

24. Pavia, D.L.; Lampman, G.M.; Kriz, G.S.; Vyvyan, J.R. Introduction to Spectroscopy, 4th ed.; Cengage Learning: Stamford, CT, USA, 2008; pp. 237-297.

25. Faig, J.J.; Klein, S.; Ouimet, M.A.; Yu, W.; Uhrich, K.E. Attenuating Oxidative Stress Via Oxalate Ester-Containing Ferulic Acid-Based Poly(anhydride-esters) that Scavenge Hydrogen Peroxide. Macromol. Chem. Phys. 2016, 217, 108-114. [CrossRef]

26. Liu, J.; Zhao, Y.; Zhou, Y.; Li, L.; Zhang, T.Y.; Zhang, H. Imidazolylidene carbene ligated palladium catalysis of the Heck reaction in the presence of air. Org. Biomol. Chem. 2003, 1, 3227-3231. [CrossRef] [PubMed]

27. Kim, H.R.; Min, H.; Jeong, Y.H.; Lee, S.K.; Lee, N.S.; Seo, E. Cytotoxic Constituents from the Whole Plant of Corydalis pallida. Arch. Pharm. Res. 2005, 28, 122-1227.

28. Ma, J.; Jones, S.H.; Hecht, S.M. Phenolic acid amides: A new type of DNA strand scission agent from Piper caninum. Bioorg. Med. Chem. 2004, 12, 3885-3889. [CrossRef]

29. Majumder, S.; Gipson, K.R.; Staples, R.J.; Odom, A.L. Pyrazole Synthesis Using a Titanium-Catalyzed multicomponent Coupling Reaction and Synthesis of Withasomnine. Adv. Synth. Catal. 2009, 351, 2013-2023. [CrossRef]

30. Bao, K.; Fan, A.; Zhang, L.; Zhang, W.; Cheng, M.; Yao, X. Selective demethylation and debenzylation of aryl ethers by magnesium iodide under solvent-free conditions and its application to the total synthesis of natural products. Org. Biomol. Chem. 2009, 7, 5084-5090. [CrossRef]

(C) 2019 by the authors. Licensee MDPI, Basel, Switzerland. This article is an open access article distributed under the terms and conditions of the Creative Commons Attribution (CC BY) license (http://creativecommons.org/licenses/by/4.0/). 